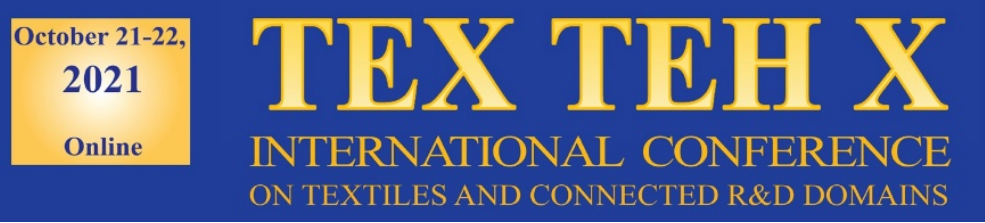

\title{
FLOATING TANK FOR TRANSPORTING OIL AND HYDROCARBONS FOLLOWING A MARITIME DISASTER
}

DOI: 10.35530/TT.2021.06

\author{
M. Jomir ${ }^{1 *}$, D. Zamirache ${ }^{2}$, A. Ene ${ }^{1}$, C. Mihai ${ }^{1}$ \\ ${ }^{1}$ National Research Development Institute for Textiles and Leather, Romania \\ (E-mail: mihaela.jomir@incdtp.ro) \\ ${ }^{2}$ Design \& Research Department, SC CONDOR SA, Romania \\ (E-mail: dan.zamfirache@condor-sa.ro)
}

\begin{abstract}
Storage of recovered oil and oily water is an important issue when it comes to maritime disasters, being a significant factor of the overall operation. Using large storage vessels is not always an option especially when the vessel is close to the shore. Currently, floating or non-inflatable tanks made of composite textile materials are used worldwide for the storage of the water/hydrocarbon mixture, regardless of the area of action (maritime or fluvial). The research carried out so far by INCDTP specialists, which consists in modelling, simulation and numerical analysis of various constructive forms and devices, led to the conclusion that for the making of a floating tank for storing water/hydrocarbon/oil mixtures, the best solution for its construction is represented by textile materials woven from high-tech yarns (p-aramid and polyamide 6.6) covered with polyurethane. The experimental model of the floating tank for the transport of oils and hydrocarbons in case of disaster was designed by INCDTP specialists and consists of five experimental models of floating materials (made of five variants of covered textile structures) and assembled in collaboration with specialists from SC CONDOR SA, in the form of a floating storage tank. The storage tank that has been created will be tested on the ground first, in order to perform all gravimetric and quality measurements.
\end{abstract}

Keywords: CAD, high-tech yarns, innovative textile technology, mobile tank, skimmer

\section{INTRODUCTION}

The consequences of marine disasters are multiple and affect particularly:

- $\quad$ the environment: oil slicks have triggered big destruction to coastal fauna and flora, to sea bottom and to the habitat of numerous species,

- $\quad$ health: marine transport is a carrier of microbes and contagious diseases; in past history, it had caused the spread of serious epidemics, hence the practice of ship quarantine;

- the economy: in the specific case of hydrocarbon transport, the claim generates a chain economic consequence, such as the devaluation of the shores, the high costs incurred in beach clean-up operations, the contamination of fisheries, the technical unemployment of fishing flotilla and related jobs on shore etc.

Disasters resulting from natural hazards can cause severe environmental and infrastructural disruption and significant economic losses [1-3]. When the release is a result of a technological accident, events can exacerbate the impact of a natural disaster on the environment, because of hazardous materials, fires and explosions (figure 1) [4,5]. In this 
respect, one of the most conspicuous forms of damage to the aquatic environment is oil pollution [5-7].
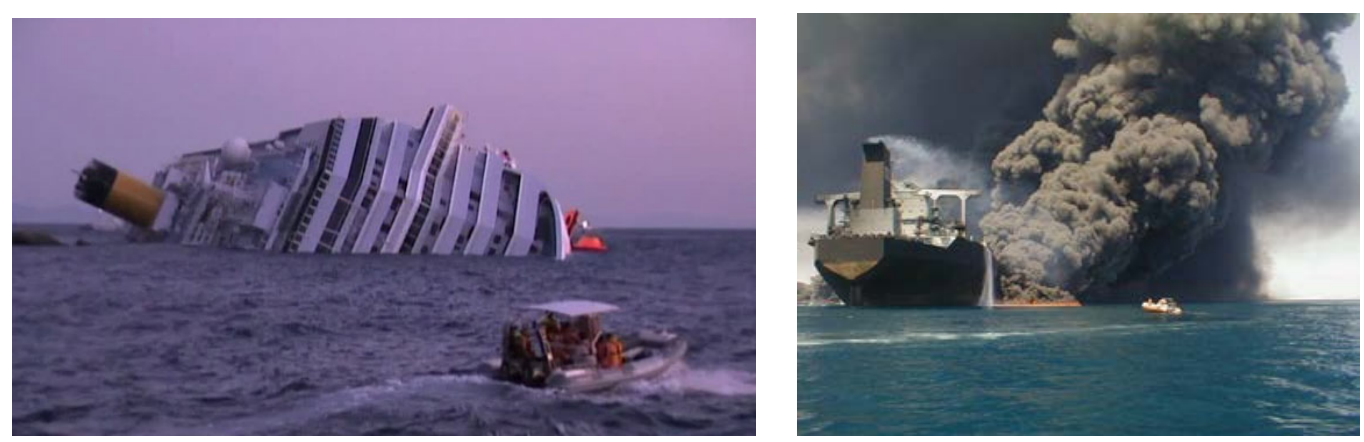

Figure 1. Sheep disasters [5]

Oil represents a broad range of hydrocarbon-based substances (crude oil and refined petroleum products, animal fats, vegetable and non-petroleum oils) with a complex physical and chemical properties [4-7]. Oil spills may be due to releases of crude oil from tankers, offshore platforms, drilling rigs and wells, as well as spills of refined petroleum products (ex. gasoline, diesel) and their by-products, heavier fuels used by large ships (bunker fuel), but it is very difficult to precisely estimate global oil inputs into marine environment. For example, around 35\% comes from tanker traffic and other shipping operations. Together with inputs from industrial effluents and oil rigs, it accounts for $45 \%$ (figure 2) [7-9].

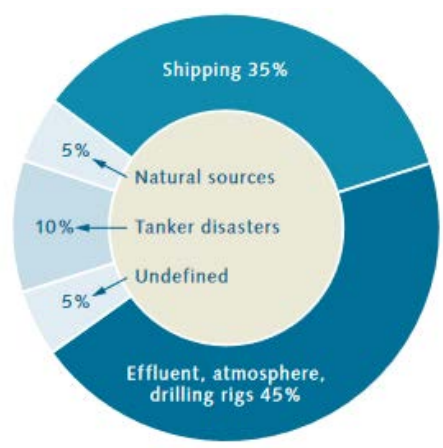

Figure 2. Various pathways of oil entering the sea [7]

Factors which affect the ability of an oil spill to spread are:

- surface tension - the higher oil's surface tension, the more likely a spill remain in place $[4,8,9]$; if the surface tension of the oil is low, it will spread even without help form wind and water currents $[4,9,10]$; supplementary, oil is more likely to spread in warmer waters than in cold waters (increased temperature reduce a liquid's surface tension);

- specific gravity - can increase if the lighter substances within the oil evaporate; heavier, vegetable oils and animal fats may sink and form tar balls or may interact with rocks or sediments on the bottom of the water body;

- viscosity - the higher the viscosity of oil, the greater the tendency for it to stay in one place $[4,8,11]$.

Oil inputs include volatile constituents which are emitted into the atmosfere during various types of burning process and after enter the water (figure 3). The brake down of the petroleum hydrocarbons depend on a variety of different environmental conditions: temperature, nutrient content in the water, wave actions etc. During the first few hour or even the first few weeks, the oil is modified by various physical, chemical and biological 
processes: evaporation of volatile constituents spreading of the spilled oil in large oil slicks drifting on surface water; formation of dispersions and emulsions; photo-oxidation (molecular changes) and solution [4,12,13]. Other processes (sedimentation and breakdown by bacteria may continue months or years $[13,14]$. The speed of breakdown depends on:

- the molecular structure of the oil constituents - the more complex the petroleum hydrocarbon molecules, the longer process for the oil breaking down by microorganisms;

- the cumulative action of the complex factors for promoting bacterial activity - high temperatures, large surface area, good oxygen and nutrient supply and low number of predator organisms.

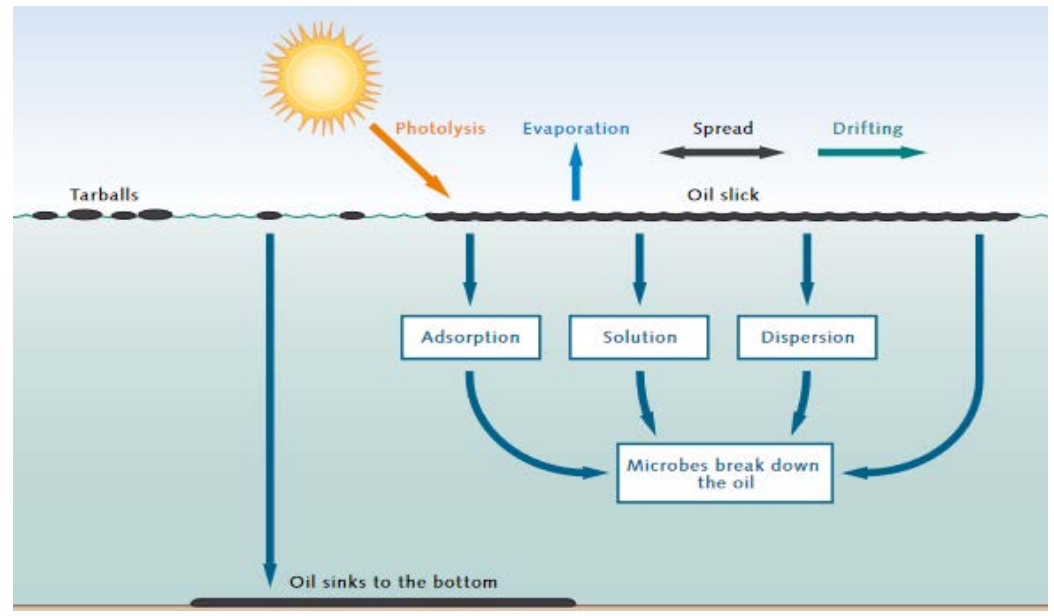

Figure 3. Modification of the crude oil in the sea [8]

There are a few solutions to respond to marine oil spills. Each of them is used according to the gravity of the situation, the surface polluted with oil and the weather conditions on the sea.

When oil (petroleum, crude oil) occurs on water, it is critical to constrain the spill as quickly as possible in order to minimize danger and potential damage to sea resources.

In this respect, [8-10] two major steps involved in controlling oil spills are:

1. containment - using floating barriers - booms to restrict the spread of oil and to allow for its recovery, removal, or dispersal (figure 44) and
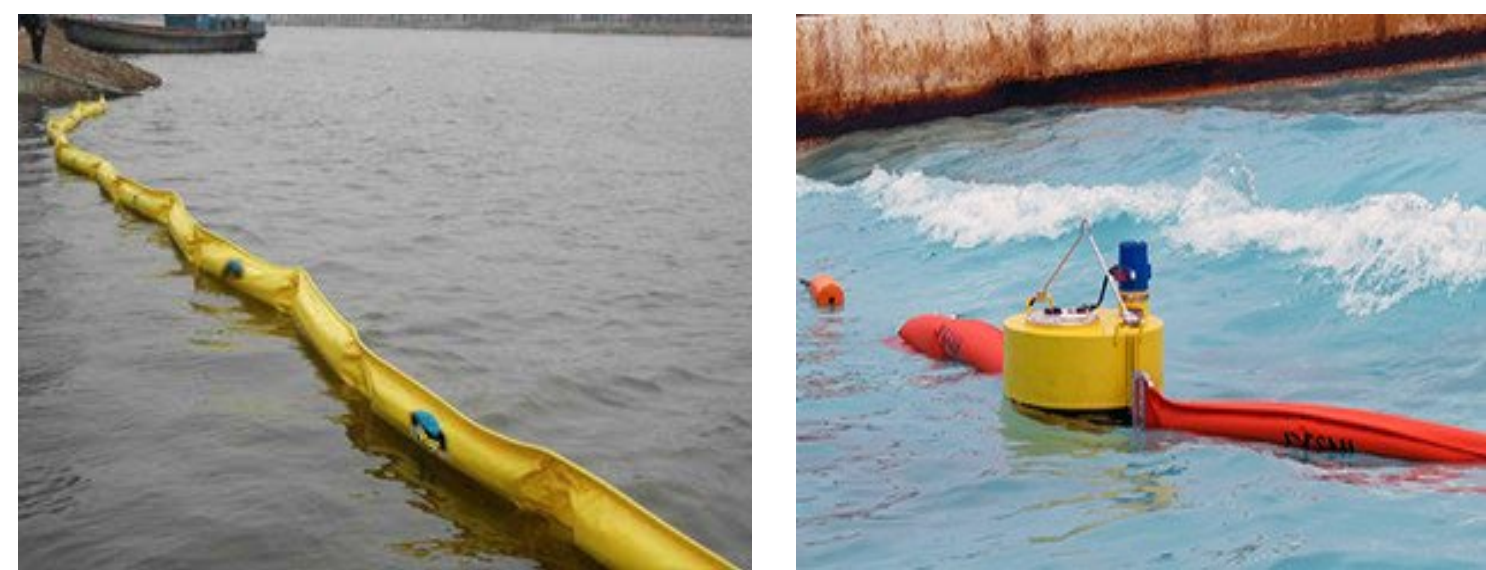

Figure 4. Anti-oil barrier [9] 
2. recovery - with three different types of equipment - booms, skimmers and sorbents. Variation in the design and construction (typo-dimensional characteristics of booms for containment) are linked with four basic characteristics [10-13]:

- above-water freeboard to contain the oil and to help prevent waves from splashing oil over the top of the boom;

- flotation device;

- below-water skirt to contain the oil and help reduce the amount of oil lost under the boom;

- longitudinal support along the bottom of the skirt, that strengthens the boom against wind and wave action (figure 1 ).

When used in recovering oil, booms are often supported by a horizontal arm extending directly off one or both sides of a vessel, forming a "U"- or "J"-shaped pocket in which oil can collect; trapped oil can be pumped out to holding tanks (shuttles) for transporting to shore for proper disposal and recycling [9-11,13]. Skimmers (type weir, oleophilic and suction, depending on type of oil being cleaned up, condition of the aquatic environment, in presence of ice or debris in water) - figure 5 may be self-propelled or may be used from shore or operated from vessels.
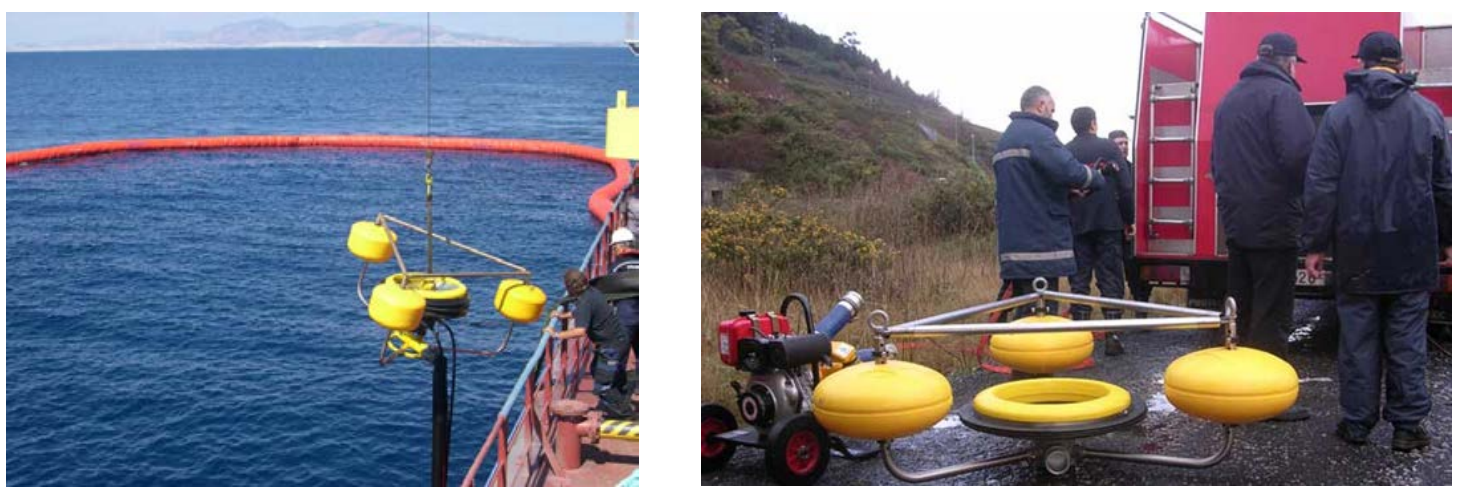

Figure 5 - Skimmers [9]

Sorbents are materials used to recover oil through the mechanisms of absorption, adsorption or both.

For a modern unit (figure 6), the following functional characteristics are required: operational in strong sea currents oil spill recovery (min. 4bf), transport and storage (at min 2kt); rapid response in an emergency (possibility to be used in max. $1 \mathrm{~h}$ in conjunction with oil spill recovery equipment: vessel, booms, skimmers etc.); hydrodynamic configuration providing stable and secure storage solutions; added design features to aid clean up and separation; light, compact and highly portable.
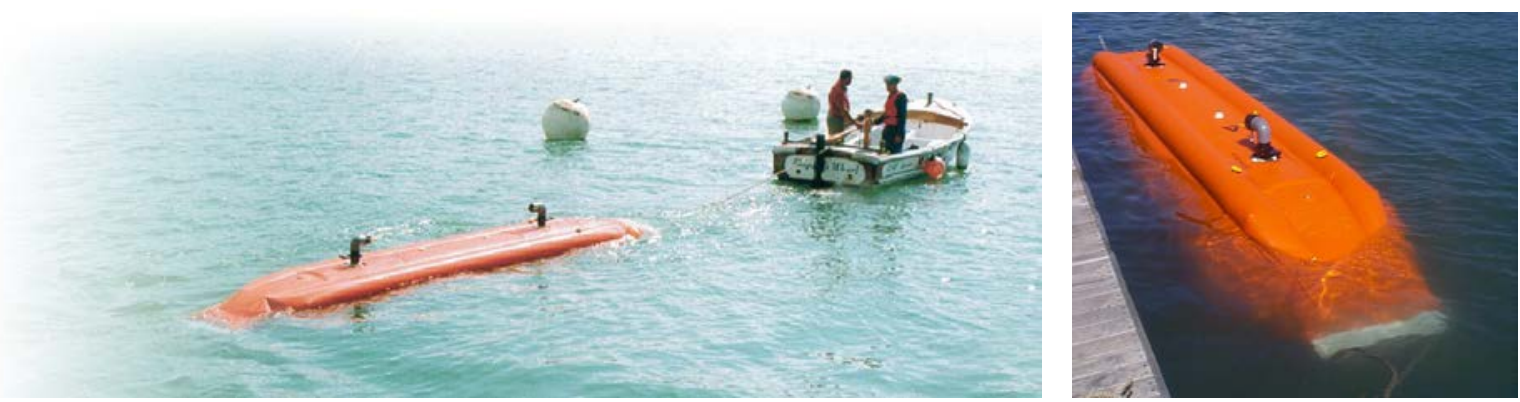

Figure 6. Horizontal tanks 
Furthermore, petroleum hydrocarbon fractions contain a wide range of individual hydrocarbon compounds and variations in physicochemical properties such as volatility and solubility need to be taken into consideration when considering the textile- reinforced composite materials for naval emergency shuttle.

\section{MATERIALS AND METHODS}

The research carried out so far by INCDTP specialists, which consists in modelling [14-18], simulation and numerical analysis of various constructive forms and devices by INCDTP specialists, made on the equipment from SC Majutex SA. The identification data of the 3 textile versions are presented below in table 1 .

The experimental models in the composition of the tank are differentiated by: the geometric shapes, the dimensions of the realization and the types of variants of composite materials used for construction [19-24].

These aspects are presented centrally in table 1.

Table 1. Textile structures/versions

\begin{tabular}{|c|c|c|c|}
\hline Characteristics & Structure 1 (V1) & Structure 2 (V2) & Structure 3 (V3) \\
\hline $\begin{array}{c}\text { Raw material } \\
\text { Warp/Weft }\end{array}$ & $100 \%$ Kevlar/ & $100 \%$ Kevlar/ & $100 \%$ Kevlar/ \\
& $100 \%$ Kevlar & $50 \%$ Kevlar/50\%PA6.6 & $100 \%$ PA6.6 \\
\hline Weave type & Plain weave & Plain weave & Plain weave \\
\hline $\begin{array}{c}\text { Finishing } \\
\text { type/colour }\end{array}$ & Covered with PU/orange & Covered with PU/orange & Covered with PU/orange \\
\hline
\end{tabular}

The experimental models in the composition of the tank are differentiated by: the geometric shapes, the dimensions of the realization and the types of variants of composite materials used for construction. These aspects are presented centrally in table 2.

Table 2. Experimental models of the composite modules

\begin{tabular}{|c|c|c|c|c|c|}
\hline Characteristics & ME15 & ME16 & ME17 & ME18 & ME19 \\
\hline $\begin{array}{c}\text { Composite material } \\
\text { - variant }\end{array}$ & V1 & V2 & V2 & V3 & V3 \\
\hline Constructive form & $\begin{array}{c}\text { Straight circular } \\
\text { cylinder }\end{array}$ & $\begin{array}{c}\text { Straight } \\
\text { circular } \\
\text { cylinder }\end{array}$ & $\begin{array}{c}\text { Straight } \\
\text { circular } \\
\text { cylinder }\end{array}$ & Cone & $\begin{array}{c}\text { Frustum of a } \\
\text { cone }\end{array}$ \\
\hline
\end{tabular}

The experimental model of the floating tank for the transport of oils and hydrocarbons in case of disaster was designed by INCDTP specialists and consists of five experimental models of floating materials (made of five variants of covered textile structures) and assembled in collaboration with specialists from SC CONDOR SA, in the form of a floating storage tank (figure 7).

\section{RESULTS AND DISCUSSIONS}

The constructive dimensions of the experimental models from the floating storage tank component were the following (figure 4):

- ME15: bases $1200 \mathrm{~mm}$, length $3600 \mathrm{~mm}$;

- ME16 and ME17: bases 300 mm, length $2400 \mathrm{~mm}$;

- ME18: base $1200 \mathrm{~mm}$, height $1000 \mathrm{~mm}$;

- ME19: large base $1200 \mathrm{~mm}$, height $800 \mathrm{~mm}$, small base $200 \mathrm{~mm}$. 


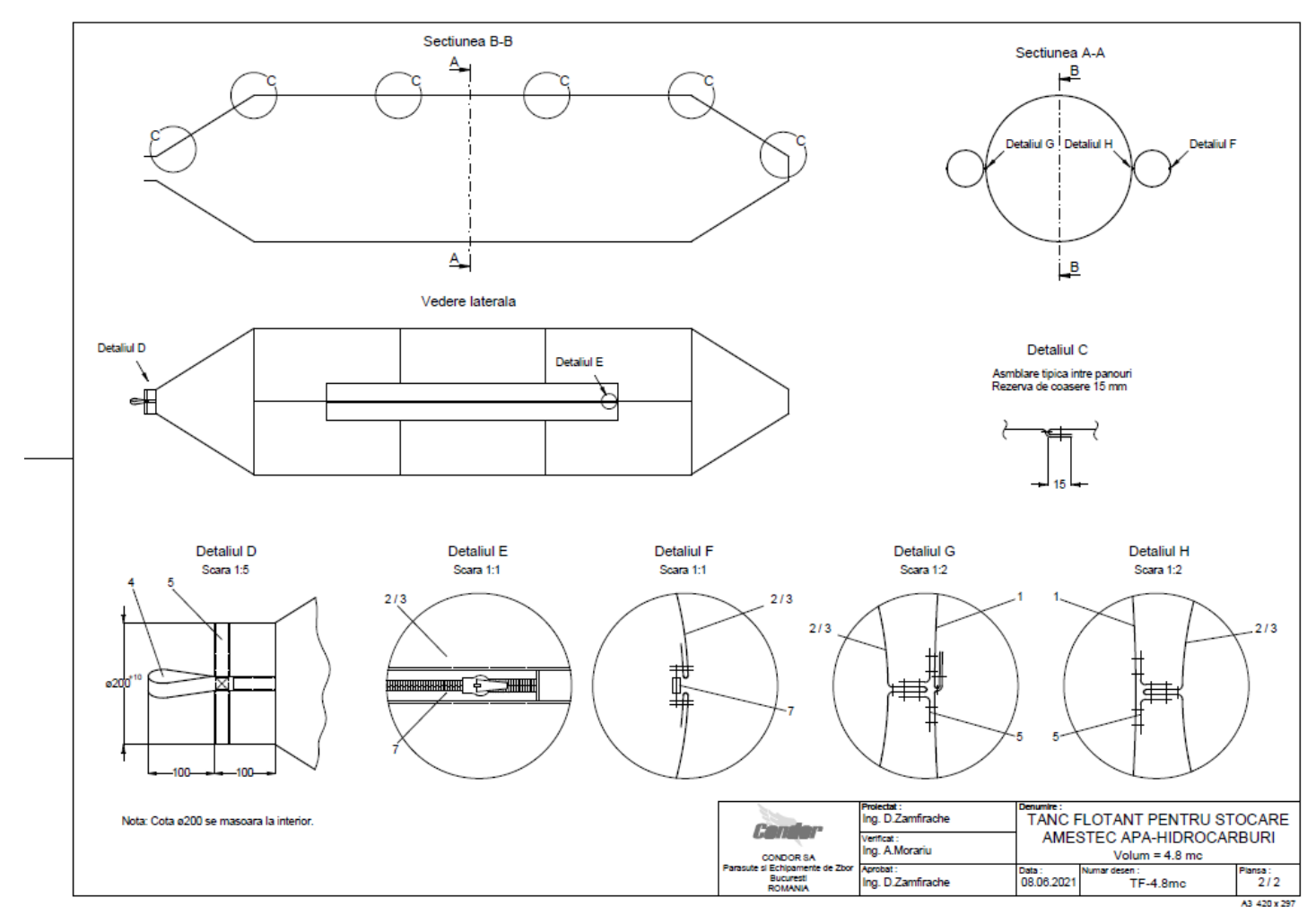

Figure 7. Sections and details for ME15 - ME19

The designed experimental models were assembled using sewing assembly technology, but using special equipment adapted for sewing para-aramid structures (figure 8).
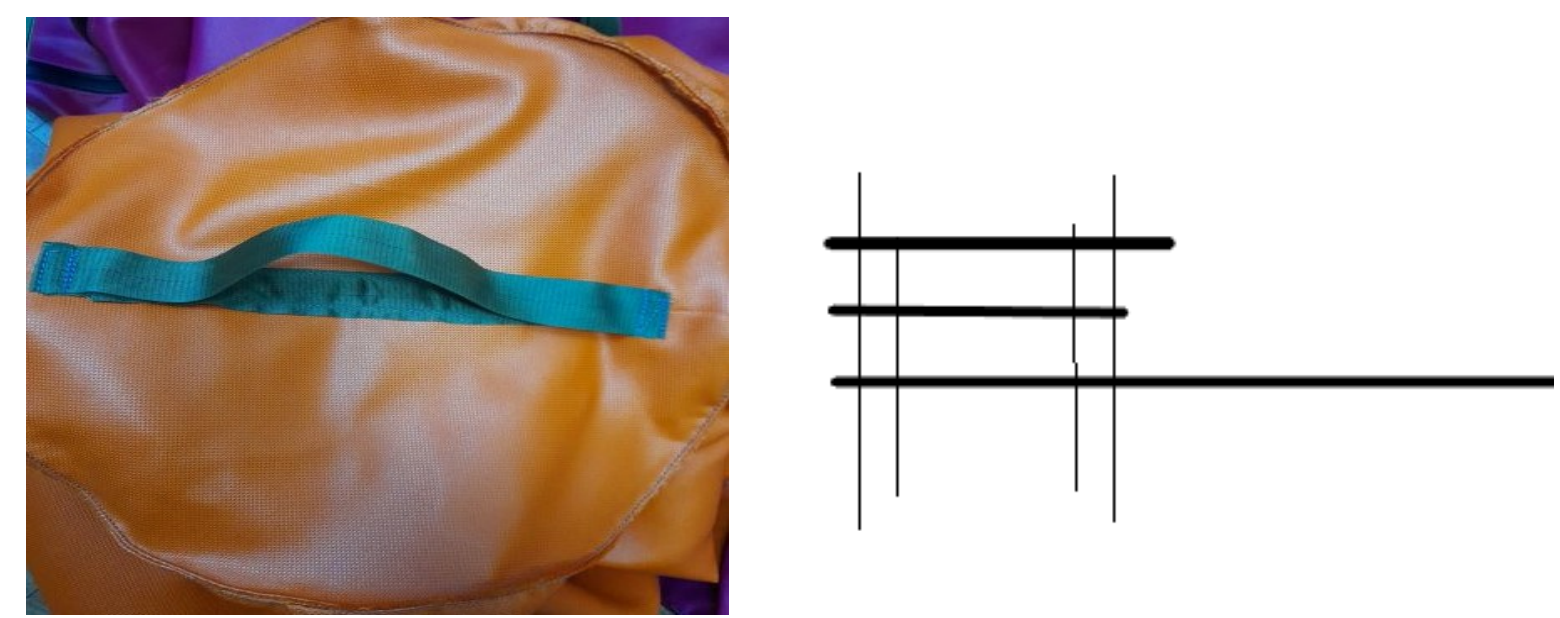

Figure 8. Sewing para-aramid structures

Particular attention was paid to the fact that there must be no bases between ME15, ME18 and ME19, in order to allow access to the mixture of water/hydrocarbons/oil recovered inside the tank to be transported to shore.

To assemble the Kevlar parts, the edge of the cut parts was stabilized by a 301 "safe stitch” using Nylon 135 Tex sewing thread, needle size 140/22 and Pfaff 2235 sewing machine with Ecodrive servomotor. A binding with scalloped edge Petersham type $30 \mathrm{~mm}$ was used to cover the edges, in order to eliminate the curling/wrinkling of the material during sewing (figure 9). 

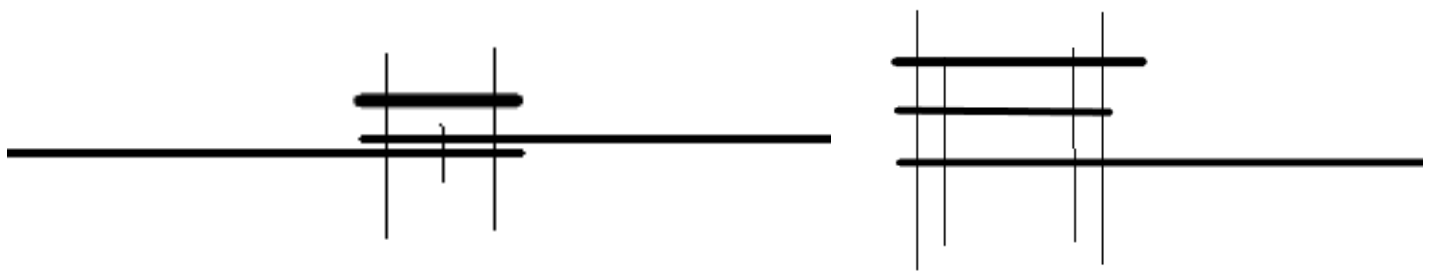

Figure 9. Elimination of the curling/wrinkling of the material during sewing

When assembling the rectangle with the circle on the straight circular cylinder, the sewing machine with two retractable needles and $25 \mathrm{~mm}$ wide grosgrain were used. Zippers with water-resistant tape and zipper strap reinforcement seams (ME16, ME17) were also used.

For ME18 and ME19, the assembly of the parts was done with reinforcing strips superimposed on each other - grosgrain $25 \mathrm{~mm}$ wide and binding with scalloped edge (Petersham), to cover and strengthen the edges of the cone and of the frustum of the cone.

The experimental model of floating tank will be tested on the ground, to verify the gravimetric measurements, as well as in real conditions of use, in the Port of Constanta.

\section{CONCLUSIONS}

The structural analysis that has been performed, on the basis of which the composite materials made of high-tech yarns were designed and made, forms the basis for the realization of the experimental models of modules from the floating tank component for storing water/hydrocarbon mixtures.

The experimental model of floating tank was made on the specific technology of assembling high-tech materials, which involves, on the one hand, the combination of large modules and, on the other hand, the use of special accessories for assembling composite textiles made of high tenacity polyamide or yarn of type p-aramid.

The storage tank that has been created will be tested on the ground first, in order to perform all gravimetric and quality measurements. It will then be tested in real experimental conditions in the Port of Constanta in order to establish the technical resource.

\section{REFERENCES}

[1] Legea nr.310/28.06.2004 pentru modificarea şi completarea Legii apelor nr.107/25.09.1996

[2] IMP, International Maritime Organisation (IMO), Guidelines for Sampling and Identification of Oil Spills - Manual on Oil Pollution, 2012

[3] TDGR, Transportation of Dangerous Goods Regulations, Available at: https://www.tc.gc.ca/eng/tdg/clear-tofc-211.htm [Accessed on June 2021]

[4] Brown, L., Probleme globale ale omenirii. Starea lumii, Editura Tehnica, București, 2001, 78-93

[5] BP America Inc, Waste Management Handbook, Guidance for Pre-Planning, Preparedness and response to Emergency Response Events, 2012

[6] Angelescu, A., Ponoran, I., Ciobotaru, Mediul ambiant şi dezvoltarea durabila, Editura

A.S.E., Bucureşti, 1999, 13-25

[7] Scotian Basin Exploration Project - Oil response plan, Annex E - Waste Management Tactical Response Plan, 2020, 166-208 
[8] *** Sendai framework for disaster risk reduction 2015- 2030,Geneva: United Nations Office for Disaster Risk Reduction, 2015, Available at: http://www.preventionweb.net/files/43291_sendaiframeworkfordrren.pdf [Accessed on June 2021]

[9] *** World Ocean Review, WOR 5 - Coasts. A Vital Habitat Under Pressure 2019, Cap 1 Coastal Dynamics, 93-102

[10] *** The cyanide spill at Baia Mare, Romania: before, during and after. Geneva:

United Nations Environment Programme/Office for the Coordination of Humanitarian Affairs, 2002, Available at: http://archive.rec.org/REC/Publications/CyanideSpill/ENGCyanide.pdf

[Accessed on June 2021]

[11] Leaning, J., Guha-Sapir, D., Natural disasters, armed conflict, and public health, New England Journal of Medicine, 2013, 369, 1836-1842, https://doi.org/10.1056/NEJMra1109877

[12] *** Chemical releases caused by natural hazard events and disasters, Geneva: World Health Organization, 2018, 16-28

[13] European Comission - Best Available Techniques Guidance Document on up stream hydrocarbon exploration and production, 25 February 2019, 124-193

[14] Ravi, S., Iyengar, N.G.R., Kishore, N.N., Shukla, A., Influence of Fiber Volume Fraction on Dynamic Damage in Woven Glass Fabric Composites: An Experimental Study, In: Adv.

Composite Mater., 2020, 9, 319-334

[15] Ghionea, I.C., Proiectare asistata in CATIA V5. Elemente teoretice si aplicatii, Ed. Bren, 2015, 210-250

[16] Wen, C., Yazdani, S., Anisotropic damage model for woven fabric composites during tensiontension fatigue, In: Composite Structures, 2008, 82, 127-131

[17] Kuo, W.S., Ko, T.H., Chen, C.P., Effect of Weaving Processes on Compressive Behavior of 3D Woven Composites, In: Composites: Part A, 2007, 38, 555-565

[18] Hallal, A., Younes, R., Fardoun, F., Nehme, S., Improved analytical model to predict the effective elastic properties of $2.5 \mathrm{D}$ interlock woven fabrics composite, In: Composite Structures, 2012, 94, 3009-3028

[19] Colorado, H.A., Chaves Roldán, C., Vélez, J.M., Internal Friction and Anaelstic Behavior in Solids, In: Dyna, 2006, 73, 39-49

[20] Scardino, F., An Introduction to Textile Structures and Their Behavior. Textile Structural Composites, In: Composite Materials series, eds. Chou T.W. and Ko F.K, Elsevier, 1989, 3

[21] Gibson, L.B., Cumiskey, S., Macosko, C.W., Compaction of Fiber Reinforcements, In: Polymer Composites, 2002, 23, 307-318

[22] Gu, H., Tensile behaviours of woven fabrics and laminates, In: Materials and Design, 2007, 28, 704-707

[23] Wan, Y.Z., Wang, Y.L., Dong, X.H., Cheng, G.X., Comparison of Mechanical Performance and Fracture Behavior of Gelatin Composites Reinforced With Carbon Fibers of Different Fiber Architectures, In: Polymer Composites, 2001, 22, 111-117

[24] Mahadik, Y., Robson Brown, K.A., Hallett, S.R., Characterisation of $3 D$ woven composite internal architecture and effect of compaction, In: Composites: Part A, 2010, 41, 872-880 